\title{
USIA HARAPAN HIDUP DENGAN RETINOPATI DIABETIK
}

\author{
${ }^{1}$ Eksys G. Kanine \\ ${ }^{2}$ Harry J. G. Sumual \\ ${ }^{2}$ Laya Rares
}

\author{
${ }^{1}$ Kandidat Skripsi Fakultas Kedokteran Universitas Sam Ratulangi \\ ${ }^{2}$ Bagian Ilmu Kesehatan Mata BLU RSUP Prof. Dr. R. D. Kandou Manado \\ Email: eksys.ek@gmail.com
}

\begin{abstract}
Life expectancy is a year life estimation from individual that stay in a region from a certain cluster of life creatures and as an indicator to see the raising of inhabitant prosperous in general way, and raising of health degree in particular way. North Sulawesi is on $3^{\text {rd }}$ place of the highest life expectancy in Indonesia. Higher life expectancy of a country or region it means higher risk too increase the incident of degenerative diseases or metabolic disorder disease, for example is diabetes mellitus. Indonesia is on $4^{\text {th }}$ place with the most incident of diabetes mellitus after China, USA, and India. Diabetic retinopathy is the most common complication from diabetes and the prominet cause of blindness in productive age.This research is belong to descriptive retrospective design with 205 sample at BLU RSUP Prof. R. D Kandou Manado. This research purpose is want to see if the increase of life expectancy affect on diabetic retinopathy incident from the young age till old age. Conclusion : And the result is didn't get any significant raising of diabetic retinopathy incident from young age till old age.
\end{abstract}

Keywords: life expectancy, diabetic retinopathy, age.

\begin{abstract}
Abstrak: Usia harapan hidup adalah perkiraan jumlah tahun hidup dari individu yang berdiam di suatu wilayah dari sekelompok makhluk hidup tertentu dan merupakan indikator dalam melihat peningkatan kesejahteraan penduduk pada umumnya, dan peningkatkan derajat kesehatan pada khususnya. Sulawesi Utara menempati urutan ketiga dengan angka usia harapan hidup tertinggi di Indonesia. Semakin tinggi usia harapan hidup suatu negara atau daerah maka semakin tinggi pula angka kejadian untuk penyakit-penyakit degeneratif ataupun penyakit gangguan metabolik contohnya seperti diabetes mellitus. Indonesia adalah negara keempat dengan penyandang diabetes mellitus terbanyak didunia setelah China, USA, dan India. Retinopati diabetik adalah komplikasi tersering dari diabetes mellitus dan merupakan faktor utama penyebab kebutaan di usia produktif. Penelitian ini merupakan penelitian dengan desain descriptive retrospective dengan 205 sampel di BLU RSUP Prof. R. D. Kandou Manado. Penelitian dimaksudkan untuk melihat apakah dengan usia harapan hidup yang meningkat berpengaruh terhadap kenaikan yang signifikan pada angka kejadian retinopati diabetik dari usia muda sampai usia tua. Simpulan : Dari hasil penelitian ternyata tidak didapatkan peningkatan angka kejadian retinopati diabetik yang signifikan dari usia muda sampai usia tua.
\end{abstract}

Kata kunci: usia harapan hidup, retinopati diabetik, usia

Usia harapan hidup manusia tergantung pada proses penuaan yang disebabkan oleh beberapa faktor yaitu : aktivitas berlebih
(Wear and Tear Theory), hormonal( Neuroendocrinology Theory), genetik (The Genetic Control Theory), dan radikal bebas 
(The Free Radical Theory). ${ }^{1}$ Berdasarkan data statistik, Sulawesi Utara menempati peringkat ketiga dengan angka usia harapan tertinggi setelah DKI Jakarta dan D.I Yogyakarta, dan meningkat dari 73,6 tahun menjadi 74.4 tahun. Semakin tinggi usia harapan hidup, semakin besar pula kemungkinan untuk mengidap berbagai macam penyakit, salah satunya Diabetes. Resiko intoleransi glukosa meningkat pada usia lebih dari 30 tahun dan terlihat nyata pada usia lebih dari 60 tahun. $^{2}$ Diabetes mellitus adalah penyakit kronik degeneratif tersering dengan angka morbiditas dan mortalitas yang tinggi di dunia. Jumlah penderita diabetes akan diperkirakan meningkat dari 171 juta pada tahun 2000 menjadi 366 juta pada tahun $2030 .^{3}$ World Health Organization (WHO) melaporkan bahwa Indonesia menempati peringkat keempat dengan jumlah penderita DM terbanyak. ${ }^{4}$

Retinopati adalah salah satu komplikasi tersering Diabetes Mellitus baik tipe 1 maupun tipe 2 yang merupakan penyebab utama kebutaan pada usia produktif di Eropa. ${ }^{3,4,5}$ Berdasakan data epidemiologi di Asia, Amerika, Australia, dan Eropa melaporkan bahwa jumlah penderita retinopati DM akan meningkat dari 100,8 juta pada tahun 2010 menjadi 154,9 juta pada tahun 2030 dengan 30\% diantaranya terancam mengalami kebutaan. ${ }^{4}$

Tujuan dari penelitian ini adalah untuk melihat apakah dengan bertambahnya usia harapan hidup berpengaruh terhadap kenaikan angka kejadian retinopati diabetik yang signifikan dari usia muda sampai usia tua.

\section{METODE PENELITIAN}

Penelitian ini dilakukan pada bulan November-Desember 2014 di BLU RSUP Prof. R. D. Kandou Manado dengan menggunakan desain penelitian Descriptive retrospective.

Populasi dalam penelitian ini adalah seluruh data rekam medik penyandang NPDR ( Non Proliferative Diabetic Retinopathy ) dan PDR ( Proliferative
Diabetic Retinopathy ) periode Oktober 2013 sampai Oktober 2014.

Variabel penelitian terdiri dari pasien retinopati diabetik ( NPDR \& PDR ) , umur, dan jenis kelamin.

Cara pengambilan data yaitu melalui catatan rekam medik, buku stase, buku rawat jalan .

Untuk menganalisis kenaikan angka kejadian retinopati diabetik yang signifikan adalah dengan cara melihat persentase dari kelompok usia muda sampai usia tua.

\section{HASIL PENELITIAN DAN BAHASAN}

Berdasarkan hasil penelitian yang didapat dari rekam medik, buku rawat jalan dan buku stase didapatkan hasil sebagai berikut.

Tabel 1. Jumlah Penderita Retinopati Diabetik

\begin{tabular}{ccc}
\hline Diagnosis & Jumlah & Persentase \\
\hline NPDR & 198 & $77,35 \%$ \\
PDR & 7 & $2,73 \%$ \\
Undiagnosed & 51 & $19,92 \%$ \\
& 256 & $100 \%$ \\
\hline
\end{tabular}

Tabel 2. Jumlah Pasien RD Laki-laki dan Perempuan

\begin{tabular}{ccc}
\hline Jenis kelamin & Jumlah & Persentase \\
\hline Laki-laki & 86 & $41,95 \%$ \\
Perempuan & 119 & $58,05 \%$ \\
& & $100 \%$ \\
\hline
\end{tabular}

Tabel 3. Umur Terendah dan Tertinggi Pasien Retinopati Diabetik

\begin{tabular}{ccccc}
\hline \multicolumn{5}{c}{ Descriptive Statistics } \\
& $\mathrm{N}$ & Minimum & Maximum & Mean \\
\hline Umur & 256 & 29 & 84 & 58.33 \\
pasien & & & & \\
$\begin{array}{c}\text { Diagno } \\
\text { sis }\end{array}$ & 256 & 1 & 3 & 1.43 \\
$\begin{array}{c}\text { Valid N } \\
\text { (listwis } \\
\text { e) }\end{array}$ & 256 & & & \\
\hline
\end{tabular}


Tabel 4. Jumlah Pasien Retinopati Diabetik Berdasarkan Umur

\begin{tabular}{cccccc}
\hline & $<$ & $21-$ & $41-$ & $>60$ & Jumlah \\
& 20 & 40 & 60 & & \\
\hline & 0 & 9 & 109 & 87 & 205 \\
DR & $0 \%$ & $\begin{array}{c}4,4 \\
\%\end{array}$ & $\begin{array}{c}53,17 \\
\%\end{array}$ & $\begin{array}{c}42,43 \\
\%\end{array}$ & $100 \%$ \\
& & & & \\
\hline
\end{tabular}

Jumlah penderita retinopati diabetik yang tercatat dari periode Oktober 2013 Oktober 2014 adalah 256 pasien dengan jumlah pasien Non Proliferative Diabetc Retinopathy ( NPDR ) sebanyak 198 orang, Proliferative Diabetic Retinopathy ( PDR ) sebanyak 7 orang, sedangkan yang terdiagnosis retinopati diabetik tapi tidak tertera NPDR maupun PDR adalah sebanyak 51 orang. Berdasarkan hasil yang tertera di tabel 2 didapatkan bahwa pasien perempuan lebih banyak di bandingkan pasien laki-laki. Hal ini sesuai dengan hasil penelitian yang dilakukan oleh Jamaludin dkk yang mengemukakan bahwa lebih banyak pasien retinopati diabetik pada perempuan dibandingkan dengan pasien laki-laki. ${ }^{6}$ Berdasarkan teori laki-laki memang lebih beresiko mengidap diabetes pada usia $<60$ tahun daripada perempuan, namun sebaliknya pada usia $>60$ tahun perempuan lebih banyak mengidap diabetes dibandingkan dengan laki-laki.,

Berdasarkan rentang umur pasien yang tertera di tabel 3 didapatkan bahwa umur terendah pasien retinopati diabetik yang ditemukan adalah 29 tahun, sedangkan umur tertinggi adalah 84 tahun, dan tidak didapatkan peningkatan angka kejadian retinopati diabetik yang signifikan dari usia $<20$ tahun sampai lebih dari 60 tahun pada Tabel 4.

Tabel 5. Pasien NPDR

\begin{tabular}{cccccc}
\hline & $<20$ & $21-40$ & $\begin{array}{c}41- \\
60\end{array}$ & $>60$ & Jumlah \\
\hline & 0 & 8 & 103 & 87 & 198 \\
NPDR & $0 \%$ & $\begin{array}{c}4,04 \\
\%\end{array}$ & $\begin{array}{c}52,02 \\
\%\end{array}$ & $\begin{array}{c}43,94 \\
\%\end{array}$ & $100 \%$ \\
& & & & & \\
\hline
\end{tabular}

$\begin{array}{cccc}\text { Berdasarkan } & \text { data } & \text { tabel diatas } \\ \text { didapatkan dari } & 198 \text { pasien Non }\end{array}$ Proliferative Diabetic Retinopathy ( NPDR ) tidak didapatkan pasien yang berumur kurang dari 20 tahun, 8 pasien pada rentang umur 21 - 40 tahun, terbanyak pada rentang umur 41 - 60 dengan jumlah 103 pasien, dan 87 pasien pada rentang umur diatas 60. Berdasarkan data diatas dapat disimpulkan bahwa tidak terdapat peningkatan angka kejadian retinopati diabetik yang signifikan dari usia $<20$ tahun sampai $>60$ tahun. Berdasarkan teori, pola hidup adalah faktor resiko tinggi sehingga tidak menutup kemungkinan NPDR lebih banyak ditemukan pada usia 41-60 tahun ketimbang > 60 tahun. ${ }^{8}$

Tabel 6. Pasien NPDR Laki-laki

\begin{tabular}{cccccc}
\hline & $<20$ & $21-40$ & $41-60$ & $>60$ & Jumlah \\
\hline & 0 & 1 & 51 & 29 & 81 \\
NPDR & $0 \%$ & $1,23 \%$ & $62,97 \%$ & $\begin{array}{c}35,80 \\
\%\end{array}$ & $100 \%$ \\
& & & & & \\
\hline
\end{tabular}

Berdasarkan tabel diatas didapatkan dari 81 pasien Non Proliferative Diabetic Retinopathy ( NPDR ) tidak ditemukan pasien laki-laki yang berumur kurang dari 20 tahun, 1 pasien pada rentang umur 21 40 tahun, terbanyak pada rentang umur 41 - 60 tahun dengan 51 pasien, dan 29 pasien pada rentang umur di atas 60 tahun. Berdasarkan data diatas dapat disimpulkan bahwa tidak terdapat peningkatan angka kejadian yang signifikan dari usia $<20$ tahun sampai > 60 tahun pada pasien NPDR laki-laki.

Tabel 7. Pasien NPDR Perempuan

\begin{tabular}{cccccc}
\hline & $<20$ & $21-40$ & $41-60$ & $>60$ & Jumlah \\
\hline \multirow{3}{*}{ NPDR } & 0 & 7 & 51 & 59 & 117 \\
& $0 \%$ & $5,98 \%$ & $43,59 \%$ & $\begin{array}{c}50,43 \\
\%\end{array}$ & $100 \%$ \\
\hline
\end{tabular}

Berdasarkan tabel diatas didapatkan dari 117 pasien Non Proliferative Diabetic Retinopathy ( NPDR ) pada perempuan 
tidak ditemukan pasien yang berumur kurang dari 20 tahun, 7 pasien pada rentang umur 21 - 40 tahun, 51 pasien pada rentang umur 41 - 60 tahun, dan 59 pasien pada rentang umur diatas 60 tahun. Berdasarkan tabel diatas dapat disimpulkan bahwa terdapat peningkatan angka kejadian yang signifikan dari usia $<20$ tahun sampai $>60$ tahun pada pasien NPDR perempuan. Hal ini disebabkan karena diatas umur 40 tahun wanita akan mengalami Menopause yang menyebabkan terjadinya penurunan hormon Estrogen dan peningkatan hormon Oestradiol dan Testoterone yang dapat meningkatkan resiko diabetes mellitus pada perempuan Postmenopause . ${ }^{9-11}$

Tabel 8. Pasien PDR

\begin{tabular}{cccccc}
\hline & $<20$ & $21-40$ & $41-60$ & $>60$ & Jumlah \\
\hline & 0 & 1 & 6 & 0 & 7 \\
PDR & $0 \%$ & $14,29 \%$ & $85,71 \%$ & $0 \%$ & $100 \%$ \\
\hline
\end{tabular}

\section{Berdasarkan Tabel diatas} didapatkan dari 7 pasien Proliferative Diabetic Retinopathy ( PDR ) yang terdiri dari 5 pasien laki-laki dan 2 pasien perempuan. Berdasarkan data diatas dapat disimpulkan bahwa laki-laki lebih banyak mengidap PDR dibandingkan perempuan. Hal ini disebabkan akibat laki-laki cenderung tidak terlalu mengontrol kadar gula darah dengan baik dibandingkan dengan perempuan. ${ }^{8,12-14}$

Dari Tabel diatas tidak ditemukan pasien yang berumur kurang dari 20 tahun dan lebih dari 60 tahun, 1 pasien usia 21 40 tahun (37 tahun), 6 pasien pada rentang umur 41- 60 tahun. Hal ini berbeda dengan yang dipaparkan oleh National Center of Diabetes, Endocrinology, and Genetics ( NCDEG ) di Yordania bahwa Proliferative Diabetic Retinopathy ( PDR ) tidak ditemukan < 45 tahun baik pada pria maupun wanita. ${ }^{15}$ Berdasarkan teori, pola hidup adalah faktor resiko tinggi sehingga tidak menutup kemungkinan ditemukannya PDR pada usia lebih muda. ${ }^{8}$
Berdasarkan tabel diatas dapat disimpulkan bahwa tidak ditemukan adanya peningkatan angka kejadian yang signifikan dari umur $<20$ tahun sampai >60 tahun pada pasien PDR.

Tabel 9. Pasien PDR Laki-laki

\begin{tabular}{cccccc}
\hline & $<20$ & $21-40$ & $41-60$ & $>60$ & Jumlah \\
\hline & 0 & 1 & 4 & 0 & 5 \\
PDR & $0 \%$ & $20 \%$ & $80 \%$ & $0 \%$ & $100 \%$ \\
& & & & & \\
\hline
\end{tabular}

Berdasarkan tabel diatas didapatkan dari 5 pasien Proliferative Diabetic Retinopathy ( PDR ) tidak ditemukan pasien yang berumur kurang dari 20 tahun dan lebih dari 60 tahun, 1 pasien pada rentang umur 21 - 40 tahun, dan 4 pasien pada rentang umur 41 - 60 tahun. Berdasarkan tabel diatas dapat disimpulkan bahwa tidak terdapat peningkatan angka kejadian yang signifikan dari usia $<20$ tahun sampai $>60$ tahun pada pasien PDR laki-laki.

Tabel 10. Pasien PDR Perempuan

\begin{tabular}{cccccc}
\hline & $<20$ & $21-40$ & $41-60$ & $>60$ & Jumlah \\
\hline & 0 & 0 & 2 & 0 & 2 \\
PDR & $0 \%$ & $0 \%$ & $100 \%$ & $0 \%$ & $100 \%$ \\
\hline
\end{tabular}

Berdasarkan tabel diatas didapatkan dari 2 pasien Proliferative Diabetic Retinopathy ( PDR ) tidak ditemukan pasien pada rentang umur kurang dari 20 tahun, 21 - 40 tahun, dan lebih dari 60 tahun, 2 pasien tersebut berada di rentang umur 41 - 60 tahun. Berdasarkan tabel diatas dapat disimpulkan bahwa tidak terdapat peningkatan angka kejadian yang signifikan dari usia $<20$ tahun sampai $>60$ tahun pada pasien PDR perempuan.

\section{SIMPULAN}

Berdasarkan hasil dari penelitian yang dilakukan dapat ditarik kesimpulaan bahwa tidak terdapat hubungan antara usia harapan hidup dengan retinopati diabetik, 
karena tidak terdapat peningkatan angka kejadian yang signifikan dari usia $<20$ tahun sampai $>60$ tahun.

\section{SARAN}

Untuk penelitiaan ke depan disarankan untuk dapat dilakukan dengan jumlah sampel yang lebih banyak untuk dapat mengetahui peningkatan angka kejadian NPDR maupun PDR yang lebih signifikan pada rentang umur tertentu.

\section{DAFTAR PUSTAKA}

1. Pangkahila AJ. Pengaturan pola hidup dan aktivitas fisik meningkatkan umur harapan hidup. 2013;1:1.

2. Reaven G. Age and glucose tolerance. 2003;26:1-2.

3. Seddon J, Fong D. Prevalence of diabetic retinopathy in various ethnic groups.Surv Opthamol. 2012;57:347.

4. Sitompul R. Retinopati diabetik. J Indon Med Assoc. 2011;61:337-9.

5. National Eye Institute. Diabetic Retinopathy. [cited 2014 Sept 17]. Available from: ttps://www.nei.nih.gov/health/diabeti c/retinopathy

6. Jamaludin, Qureshi MB, Khan AJ, Khan MD, Ahmad K. Prevalence of diabetic retinopathy among individuals screened positive for diabetes in five community based eye camps in northern karachi pakistan. J Ayub Med Coll Abbottabad. 2006;18(3):41.
7. Boelter MC, Canani LH, Lisboa HR, Lavinzky J, Azevedo MJ. Proliferative diabetic retinopathy is associated with microalbuminuria in patient with type 2 diabetes. Braz J Med Biol Res. 2006;39:1035.

8. Grady D. Management of menopausal symptoms. N Engl $\mathrm{J}$ Med. 2006:355:2338.

9. Liu S, Tinker L, Song Y, Rifai N, Bonds DE, Cook NR, et al. A prospective study of inflammatory cytokines and diabetes mellitus in multiethnic cohort of postmenopausal women. Arch Intern Med. 2007;167(15):1676.

10.Ding EL, Song Y, Manson JE, Rifai N, Buring JE, Liu S. Plasma sex steroid hormones and risk of developing type 2 diabetes in women. Diabetologia. 2007;50:2076.

11.Antonetti DA, Klein R, Gardner TW. Diabetic retinopathy. N Engl J Med. 2012;366:1227.

12.Falco M, Falco RF, Rocha SA. Diabetic retinopathy understanding pathologic angiogenesis and exploring its treatment option. 2010;3:35-9.

13.Garg S, Davis RM. Diabetic retinopathy screening update. 2009:4:142.

14.Al-amer RM, Khader Y, Malas S, AbuYaghi N, Al-Bdour M, Ajlouni $\mathrm{K}$. Prevalence and risk factors of diabetic retinopathy among jordanian patients with type 2 diabetes. 2008[cited 2014 Dec 27]:14:2. Available from : http://www.djo.harvard.edu/site.php? url=/physicians/oa/1204. 